\title{
DOSES E FONTES DE NITROGÊNIO NA PRODUTIVIDADE DO EUCALIPTO E NAS FRAÇÕES DA MATÉRIA ORGÂNICA EM SOLO DA REGIÃO DO CERRADO DE MINAS GERAIS(1)
}

\author{
Guilherme Luiz de Jesus ${ }^{(2)}$, Nairam Félix de Barros ${ }^{(3)}$, Ivo Ribeiro da \\ Silva ${ }^{(4)}$, Julio César Lima Neves ${ }^{(4)}$, Eduardo Pinheiro Henriques ${ }^{(5)}$, \\ Vinicius Campos Lima ${ }^{(6)}$, Loane Vaz Fernandes ${ }^{(7)}$ \& Emanuelle Merces
}

Barros Soares $^{(4)}$

\begin{abstract}
RESUMO
Apesar da grande quantidade de $\mathrm{N}$ acumulada em plantações de eucalipto de alta produtividade, o aumento em volume do tronco em resposta à aplicação de $\mathrm{N}$ não tem sido expressivo nem consistente. $\mathrm{O}$ objetivo deste trabalho foi verificar o efeito de doses e fontes de $\mathrm{N}$ sobre o crescimento e o acúmulo de $\mathrm{N}$ em plantas de eucalipto, na serapilheira, além do impacto nas frações da matéria orgânica do solo (MOS). O experimento foi instalado em campo, no município de Itamarandiba-MG, em blocos ao acaso com três repetições, consistindo da aplicação em cobertura de doses $\left(0,60,120\right.$ e $\left.240 \mathrm{~kg} \mathrm{ha}^{-1}\right)$ e fontes de $\mathrm{N}$ distintas (sulfato de amônio e nitrato de amônio) em clone de eucalipto (AEC1528 ${ }^{\circledR}$ ). O efeito dos tratamentos sobre o crescimento e acúmulo de $\mathrm{N}$ nas plantas foi avaliado aos 30 meses de idade, abatendo-se árvores com DAP médio e separando-as em lenho, casca, galhos e folhas, para determinação da produção de matéria seca e dos teores e conteúdos de nutrientes das plantas. Amostras de solo e de serapilheira foram coletadas para análises de nutrientes. Os teores de $\mathrm{C}$ e $\mathrm{N}$ total da matéria orgânica particulada (MOP) e da matéria orgânica associada à fração mineral (MOAM) foram determinados por espectrometria de massa de razão isotópica, após separação física da MOS. As análises estatísticas consistiram de análise de variância e de regressão. A aplicação de adubos nitrogenados promoveu aumento no crescimento volumétrico do tronco e na matéria seca da parte aérea.
\end{abstract}

\footnotetext{
(1) Recebido para publicação em 27 de outubro de 2011 e aprovado em 8 de novembro de 2011.

(2) Doutorando em Solos e Nutrição de Plantas, Departamento de Solos, Universidade Federal de Viçosa - UFV. Av P H Rolfs s/n, CEP 36570-000 Viçosa (MG). E-mail: guilherme.jesus@cenibra.com.br

(3) Professor Titular do Departamento de Solos, UFV. E-mail: nfbarros@ufv.br

(4) Professor Adjunto do Departamento de Solos, UFV. E-mail: ivosilva@ufv.br; julio_2003@yahoo.com.br; emanuelle.soares@ufv.br

(5) Engenheiro Florestal, ArcelorMittal. Avenida Carandaí 1115, 23º andar - Centro, CEP 30130-915 Belo Horizonte (MG). E-mail: eduardo.henriques@arcelormittal.com.br

(6) Engenheiro Agrônomo, Tv. Felício Brandi 40, CEP 36570-000 Viçosa (MG). E-mail: canpvinicius@bol.com.br

(7) Doutorando em Solos e Nutrição de Plantas, Departamento de Solos, UFV. E-mail: loane@gmail.com
} 


\begin{abstract}
A dose de $\mathrm{N}$ como sulfato de amônio para obter 90 \% da produção máxima foi de $74 \mathrm{~kg} \mathrm{ha}^{-1}$, a qual resultou em incremento de $42,3 \%$ no volume de tronco em relação à testemunha sem adubação nitrogenada. Na dose de $120 \mathrm{~kg} \mathrm{ha}^{-1} \mathrm{de} \mathrm{N}$, não houve diferença de resposta à aplicação de sulfato de amônio e nitrato de amônio. Não foram detectadas alterações nos estoques de $\mathrm{C}$ e $\mathrm{N}$ da MOS com a adubação nitrogenada. No entanto, houve aumento da absorção de Ca, $\mathrm{Mg}$ e S. A taxa de recuperação aparente de $\mathrm{N}$ no campo foi maior na dose de $120 \mathrm{~kg} \mathrm{ha}^{-1}$ de $\mathrm{N}$, atingindo $34,4 \%$.
\end{abstract}

Termos de indexação: amônio, Eucalyptus sp., matéria orgânica do solo, nitrato, serapilheira.

\title{
SUMMARY: EFFECT OF NITROGEN RATES AND SOURCES ON EUCALYP- TUS YIELD AND SOIL ORGANIC MATTER FRACTIONS IN THE CERRADO REGION OF MINAS GERAIS
}

\begin{abstract}
In spite of the high amount of $N$ accumulated in high-yielding, short-rotation eucalyptus plantations, no significant or consistent increases in trunk volume have been observed in response to $N$ fertilization. This experiment evaluated the effect of $N$ fertilization on the growth and chemical composition of eucalyptus as well as its role in soil organic matter (SOM) mineralization. The field experiment was carried out in a randomized block design with three replications, in Itamarandiba- $M G$. Two $N$ sources (ammonium sulphate and ammonium nitrate) of increasing $N$ rates $\left(0,60,120,240 \mathrm{~kg} \mathrm{~h}^{-1}\right)$ were tested on the eucalyptus clones AEC1528 ${ }^{\circledR}$. The effect of the treatments on tree growth and $N$ accumulation were evaluated in 30 month-old trees with average DBH, which were harvested and separated in stem, bark, branches, and leaves to determine dry matter production and nutrient contents. Soil and forest litter samples were collected for chemical analyses. Total $C$ and $N$ content of particulate organic matter (POM) and organic matter associated to the mineral fraction (OMAM) were quantified by mass spectrometry (IRMS) after physical separation of SOM. The statistical analyses consisted of variance analysis and regression. Nitrogen fertilization increased trunk volume and aerial dry matter. The estimated $N$ rate to obtain $90 \%$ of the maximum trunk volume was $74 \mathrm{~kg} \mathrm{ha-1}$ in the form of ammonium sulfate, and increased the yield by $42.3 \%$ in comparison to the control plot without $N$ fertilization. In response to $N$ rates of $120 \mathrm{~kg} \mathrm{ha} \mathrm{g}^{-1}$, no difference was observed between ammonium sulfate and ammonium nitrate. No alterations in SOM C and N stocks were detected due to N application. However, there was an increase in $\mathrm{Ca}, \mathrm{Mg}$ and $\mathrm{S}$ absorption. The apparent $\mathrm{N}$ recovery rate in the field was highest at the $\mathrm{N}$ rate of $120 \mathrm{~kg} \mathrm{ha} \mathrm{H}^{-1}$, reaching $34.4 \%$.
\end{abstract}

Index terms: Ammonium, Eucalyptus sp., soil organic matter, nitrate, forest litter.

\section{INTRODUÇÃO}

A produtividade das plantações comerciais de eucalipto no Brasil é bastante variável (15 a $80 \mathrm{~m}^{3}$ ha $^{-1}$ ano $^{-1}$ de madeira) e dependente da disponibilidade de água e de nutrientes (Barros \& Comerford, 2002). A demanda nutricional é proporcional à produtividade florestal (Gonçalves et al., 1997), com o acúmulo de $\mathrm{N}$ na biomassa chegando a valores acima de uma tonelada por hectare (Barros et al., 1990).

$\mathrm{O} \mathrm{N}$ é o nutriente que se encontra em maiores concentrações nos vegetais superiores. Sua participação no metabolismo tem sido bastante estudada na maioria das espécies cultivadas, principalmente as de ciclo anual, mas poucos estudos têm sido conduzidos com espécies florestais em condições tropicais.

O eucalipto pode responder à fertilização, particularmente com $\mathrm{N}$, aumentando a área foliar, com consequente aumento de volume de tronco (Smethurst et al., 2003). Em povoamentos florestais, a quantidade de $\mathrm{N}$ acumulado pode ir de 120 a $1.300 \mathrm{~kg} \mathrm{ha}{ }^{-1}$, dependendo das condições edafoclimáticas, do material genético e da produção do povoamento (Barros et al., 1990). Apesar da grande quantidade de $\mathrm{N}$ que pode ser acumulada nesses plantios, o aumento em volume e biomassa 
em resposta à aplicação de $\mathrm{N}$ não tem sido expressivo (Valeri, 1983 apud Barros et al., 1990; Santos, 2001). A ausência ou pequena resposta do eucalipto à adubação nitrogenada pode ser atribuída à maior quantidade de $\mathrm{N}$ mineralizado da matéria orgânica do solo (Gama-Rodrigues, 1997; Pulito, 2009). O $\mathrm{N}$ mineralizável foi apontado como um importante indicador da disponibilidade de $\mathrm{N}$ em povoamentos de E. globulus em solos do Uruguai, mostrando correlação positiva com a produção volumétrica (Perdomo et al., 2007). Respostas contrastantes do eucalipto à aplicação de $\mathrm{N}$ foram verificadas em recentes observações realizadas em dois experimentos no Vale do Jequitinhonha - Minas Gerais. Numa situação, a resposta ao sulfato de amônio poderia ser atribuída ao enxofre, fato suportado pela maior resposta do eucalipto ao superfosfato simples em comparação com o superfosfato triplo. Contudo, em outro experimento, no mesmo sítio florestal, com a aplicação de $\mathrm{N}$ na forma amoniacal e na forma nítrica $\left(\mathrm{NH}_{4} \mathrm{NO}_{3}\right)$, a resposta permaneceu, indicando resposta ao N (NUTREE, dados não publicados).

Diante desses fatos e das informações da literatura, que apresentam dados contrastantes para a resposta à adubação nitrogenada de plantações florestais, fica clara a necessidade de mais estudos que avaliem o efeito da adubação nitrogenada no crescimento e na composição química de plantas de eucalipto, visando quantificar a dose adequada de $\mathrm{N}$ a ser aplicada nas adubações de cobertura. Dessa forma, este trabalho teve como objetivo verificar o efeito de doses e fontes de $\mathrm{N}$ sobre o crescimento e o acúmulo de $\mathrm{N}$ em plantas de eucalipto e na serapilheira, além do impacto nas frações da matéria orgânica do solo (MOS).

\section{MATERIAL E MÉTODOS}

\section{Descrição da área de estudo}

Este estudo foi realizado em áreas da empresa ArcelorMittal Bioenergia localizadas na região do Cerrado de Itamarandiba, Estado de Minas Gerais, situado a $17^{\circ} 51^{\prime} \mathrm{S}, 42^{\circ} 51^{\prime} \mathrm{W}$, altitude média de $1.097 \mathrm{~m}$, com precipitação pluvial média anual de $1.081 \mathrm{~mm}$ e temperatura média anual de $20,1{ }^{\circ} \mathrm{C}$. $\mathrm{O}$ experimento foi instalado no mês de junho de 2005 com o clone AEC $1528^{\circledR}$ de E. urophylla em Latossolo Vermelho-Amarelo textura muito argilosa. No plantio do eucalipto utilizou-se formulação NPK contendo $04 \%$ de N, $26 \%$ de $\mathrm{P}_{2} \mathrm{O}_{5}$ e $16 \%$ de $\mathrm{K}_{2} \mathrm{O}$, enriquecida com $1,0 \%$ de $\mathrm{Zn}$ e $0,5 \%$ de $\mathrm{Cu}$ na dosagem de $130 \mathrm{~g} /$ planta. Antes do plantio, foram aplicados $500 \mathrm{~kg} \mathrm{ha}^{-1}$ de fosfato natural de Araxá, no sulco de plantio. Realizou-se, também, a aplicação de $2.000 \mathrm{~kg} \mathrm{ha}^{-1}$ de Agrosilício $^{\circledR}$, no mês de junho de 2006, como fonte de $\mathrm{Ca}$ e $\mathrm{Mg}$. As adubações de cobertura foram realizadas em três épocas, de acordo com o tratamento: uma foi feita em janeiro, outra em março e a última em dezembro de 2006. Nas adubações de cobertura dos meses de janeiro e dezembro de 2006, todos os tratamentos receberam uma dose de $210 \mathrm{~kg} \mathrm{ha}^{-1}$ de $\mathrm{KCl}$ enriquecido com $0,5 \%$ de $\mathrm{B}$.

Os tratamentos consistiram da aplicação de 0 , 60,120 e $240 \mathrm{~kg} \mathrm{ha}^{-1}$ de N, como sulfato de amônio, em faixa de 0,5 m de largura ao lado da linha de plantio. Visando avaliar se a resposta ao sulfato de amônio era exclusivamente devido ao $\mathrm{N}$, um tratamento adicional consistiu da aplicação de $120 \mathrm{~kg} \mathrm{ha}^{-1}$ de $\mathrm{N}$ como nitrato de amônio, totalizando cinco tratamentos (Quadro 1).

Quadro 1. Quantidades de corretivos e fertilizantes utilizados na época de plantio de eucalipto e doses, fontes e épocas de aplicação em cobertura, no município de Itamarandiba-MG

\begin{tabular}{|c|c|c|c|c|c|c|c|}
\hline \multirow{2}{*}{$\begin{array}{l}\text { Trata- } \\
\text { mento }\end{array}$} & \multirow{2}{*}{ Fonte } & \multirow{2}{*}{$\begin{array}{c}\text { Fosfatagem } \\
\text { jun/05 }\end{array}$} & \multirow{2}{*}{$\begin{array}{l}\text { Adubação } \\
\text { de plantio } \\
\text { jun/05 }\end{array}$} & \multirow{2}{*}{$\begin{array}{c}\text { Fonte de Ca } \\
\text { e Mg } \\
\text { Jun/06 }\end{array}$} & \multicolumn{3}{|c|}{ Adubações de cobertura } \\
\hline & & & & & $\mathrm{jan} / 06$ & $\operatorname{mar} / 06$ & $\mathrm{dez} / 06$ \\
\hline Sem N & - & $\begin{array}{c}500 \mathrm{~kg} / \mathrm{ha} \text { de } \\
\text { Fosfato Natural } \\
\text { de Araxá }\end{array}$ & $\begin{array}{l}130 \text { g/planta de } \\
04-26-16+1 \% \\
\mathrm{Zn}+0,5 \% \mathrm{Cu}\end{array}$ & $\begin{array}{l}2.000 \mathrm{~kg} \mathrm{ha}^{-1} \\
\text { AgroSilício }\end{array}$ & $\begin{array}{l}210 \mathrm{~kg} / \mathrm{ha} \mathrm{KCl} \\
+0,5 \% \mathrm{~B}\end{array}$ & - & $\begin{array}{l}210 \mathrm{~kg} \mathrm{ha}^{-1} \mathrm{KCl} \\
+0,5 \% \mathrm{~B}\end{array}$ \\
\hline $\begin{array}{l}60 \mathrm{~kg} \mathrm{ha}^{-1} \\
\text { de N }\end{array}$ & $\begin{array}{l}\text { Sulfato de } \\
\text { Amônio } \\
\text { (S.A.) }\end{array}$ & $\begin{array}{c}500 \mathrm{~kg} \mathrm{ha} \mathrm{h}^{-1} \mathrm{de} \\
\text { Fosfato Natural } \\
\text { de Araxá }\end{array}$ & $\begin{array}{l}130 \text { g/planta de } \\
04-26-16+1 \% \\
\mathrm{Zn}+0,5 \% \mathrm{Cu}\end{array}$ & $\begin{array}{l}2.000 \mathrm{~kg} \mathrm{ha}^{-1} \\
\text { AgroSilício }\end{array}$ & $\begin{array}{l}210 \mathrm{~kg} \mathrm{ha}^{-1} \mathrm{KCl} \\
+0,5 \% \mathrm{~B}+ \\
150 \mathrm{~kg} \mathrm{ha}^{-1} \text { S.A. }\end{array}$ & - & $\begin{array}{l}210 \mathrm{~kg} \mathrm{ha}^{-1} \mathrm{KCl} \\
+0,5 \% \mathrm{~B}+ \\
150 \mathrm{~kg} \mathrm{ha}^{-1} \text { S.A. }\end{array}$ \\
\hline $\begin{array}{l}120 \mathrm{~kg} \mathrm{ha}^{-1} \\
\text { de N }\end{array}$ & $\begin{array}{l}\text { Sulfato de } \\
\text { Amônio } \\
\text { (S.A.) }\end{array}$ & $\begin{array}{c}500 \mathrm{~kg} \mathrm{ha}^{-1} \mathrm{de} \\
\text { Fosfato Natural } \\
\text { de Araxá }\end{array}$ & $\begin{array}{l}130 \text { g/planta de } \\
04-26-16+1 \% \\
\mathrm{Zn}+0,5 \% \mathrm{Cu}\end{array}$ & $\begin{array}{c}2.000 \mathrm{~kg} \mathrm{ha}^{-1} \\
\text { AgroSilício }\end{array}$ & $\begin{array}{l}210 \mathrm{~kg} \mathrm{ha}^{-1} \mathrm{KCl} \\
+0,5 \% \mathrm{~B}+ \\
150 \mathrm{~kg} \mathrm{ha}^{-1} \text { S.A. }\end{array}$ & $\begin{array}{l}150 \mathrm{~kg} \mathrm{ha}^{-1} \\
\text { S.A. }\end{array}$ & $\begin{array}{l}210 \mathrm{~kg} \mathrm{ha}^{-1} \mathrm{KCl} \\
+0,5 \% \mathrm{~B}+ \\
300 \mathrm{~kg} \mathrm{ha}^{-1} \text { S.A. }\end{array}$ \\
\hline $\begin{array}{c}240 \mathrm{~kg} \mathrm{ha}^{-1} \\
\text { de N }\end{array}$ & $\begin{array}{l}\text { Sulfato de } \\
\text { Amônio } \\
\text { (S.A.) }\end{array}$ & $\begin{array}{c}500 \mathrm{~kg} \mathrm{ha}^{-1} \mathrm{de} \\
\text { Fosfato Natural } \\
\text { de Araxá }\end{array}$ & $\begin{array}{l}130 \mathrm{~g} / \mathrm{planta} \text { de } \\
04-26-16+1 \% \\
\mathrm{Zn}+0,5 \% \mathrm{Cu}\end{array}$ & $\begin{array}{l}2.000 \mathrm{~kg} \mathrm{ha}^{-1} \\
\text { AgroSilício }\end{array}$ & $\begin{array}{l}210 \mathrm{~kg} \mathrm{ha}^{-1} \mathrm{KCl} \\
+0,5 \% \mathrm{~B}+ \\
150 \mathrm{~kg} \mathrm{ha}^{-1} \text { S.A. }\end{array}$ & $\begin{array}{l}300 \mathrm{~kg} \mathrm{ha}^{-1} \\
\text { S.A. }\end{array}$ & $\begin{array}{l}210 \mathrm{~kg} \mathrm{ha}^{-1} \mathrm{KCl} \\
+0,5 \% \mathrm{~B}+ \\
750 \mathrm{~kg} \mathrm{ha}^{-1} \text { S.A. }\end{array}$ \\
\hline $\begin{array}{l}120 \mathrm{~kg} \mathrm{ha}^{-1} \\
\text { de N }\end{array}$ & $\begin{array}{l}\text { Nitrato de } \\
\text { Amônio } \\
\text { (N.A.) }\end{array}$ & $\begin{array}{c}500 \mathrm{~kg} / \mathrm{ha} \text { de } \\
\text { Fosfato Natural } \\
\text { de Araxá }\end{array}$ & $\begin{array}{l}130 \text { g/planta de } \\
04-26-16+1 \% \\
\mathrm{Zn}+0,5 \% \mathrm{Cu}\end{array}$ & $\begin{array}{l}2.000 \mathrm{~kg} \mathrm{ha}^{-1} \\
\text { AgroSilício }\end{array}$ & $\begin{array}{l}210 \mathrm{~kg} \mathrm{ha}^{-1} \mathrm{KCl} \\
+0,5 \% \mathrm{~B}+ \\
90 \mathrm{~kg} \mathrm{ha}^{-1} \text { N.A. }\end{array}$ & $\begin{array}{l}90 \mathrm{~kg} \mathrm{ha}^{-1} \\
\text { N.A. }\end{array}$ & $\begin{array}{l}210 \mathrm{~kg} \mathrm{ha}^{-1} \mathrm{KCl} \\
+0,5 \% \mathrm{~B}+ \\
180 \mathrm{~kg} \mathrm{ha}^{-1} \text { N.A. }\end{array}$ \\
\hline
\end{tabular}


Os tratamentos foram aplicados nas parcelas, com 0,6 ha cada, com $1.714 \mathrm{~m}^{2}$ de área útil, sendo 204 plantas úteis e duas fileiras de bordadura. O espaçamento entre as árvores foi de $3 \times 2,8 \mathrm{~m}$. $\mathrm{O}$ delineamento experimental foi em blocos casualizados, em três repetições.

\section{Coleta e análises de amostras de solo}

Amostras de solo foram coletadas quando as árvores tinham 30 meses de idade, portanto, seis meses após toda a adubação nitrogenada ter sido realizada. Foram coletadas 12 amostras simples para compor uma amostra composta, dentro da faixa em que se aplicou o adubo nitrogenado, em cada parcela. A amostragem foi realizada nas camadas de solo de 0-10, 10-20, 20-40 e 40-60 cm.

As amostras foram secas ao ar, destorroadas, passadas em peneiras de $2 \mathrm{~mm}$ de malha e homogeneizadas e, posteriormente, submetidas às análises químicas e físicas (Quadros 2 e 3). Foram determinados $\mathrm{pH}$ em água; $\mathrm{Al}, \mathrm{Ca}$ e $\mathrm{Mg}$ trocáveis, extraídos com KCl $1 \mathrm{~mol} \mathrm{~L}^{-1}$; P e K extraídos pelo Mehlich-1, de acordo com método descrito por Defelipo \& Ribeiro (1997). Nos extratos, os teores de $\mathrm{P}$ foram determinados por colorimetria (Braga \& Defelipo, 1974), os de K, por fotometria de chama, e os de $\mathrm{Ca}, \mathrm{Mg}$ e Al, por espectrofotometria de absorção atômica (AOAC, 1975). Os teores de sulfato do solo foram determinados segundo método descrito por Alvarez V. et al. (2001).
Os teores de $\mathrm{Fe}, \mathrm{Mn}, \mathrm{Zn}$ e $\mathrm{Cu}$ foram determinados por espectrofotometria de absorção atômica após extração com Mehlich-1, e o B foi extraído com água quente e quantificado por colorimetria, utilizando Azometina-H (Abreu et al., 1994). O P remanescente foi determinado de acordo com Alvarez V. et al. (2000). A caracterização textural foi feita seguindose o método proposto por Ruiz (2005).

Realizou-se o fracionamento físico da MOS segundo o método proposto por Cambardella \& Elliot (1992). A fração Matéria Orgânica Particulada (MOP) foi separada da Matéria Orgânica Associada à Fração Mineral (MOAM) por meio da dispersão com solução de hexametafosfato de sódio e separação por peneira com abertura de $53 \mu \mathrm{m}$, sendo a MOP o material retido e a MOAM o material que passa através da peneira. Os teores de $\mathrm{C}$ e $\mathrm{N}$ das frações MOP e MOAM foram determinados em espectrômetro de massa de razão isotópica de fluxo contínuo (ANCA-GSL, 20-20, Sercon, Crewe, UK).

\section{Medição, coleta e análise do material vegetal}

Aos 30 meses, mediu-se o diâmetro do tronco à altura de 1,3 m (DAP) e a altura de todas as árvores da área útil da parcela. Em cada parcela, abateuse uma árvore com diâmetro correspondente ao da árvore média do respectivo tratamento. A altura comercial (definida por um diâmetro de tronco superior a $2 \mathrm{~cm}$ ) e a total foram medidas, efetuando-

Quadro 2. Características químicas de amostras de solo de um plantio de eucalipto aos 30 meses de idade (clone AEC $1528^{\circledR}$ ) sob doses e fontes de N distintas, em Itamarandiba, MG

\begin{tabular}{|c|c|c|c|c|c|c|c|c|}
\hline Dose N & Camada de solo & pH & $\mathbf{P}$ & $\mathbf{K}$ & $\mathbf{S}$ & $\mathrm{Ca}^{2+}$ & $\mathrm{Mg}^{2+}$ & $\mathrm{Al}^{3+}$ \\
\hline & & \multicolumn{3}{|c|}{$\mathrm{mg} \mathrm{dm}^{-3}$} & \multicolumn{3}{|c|}{$-\mathrm{cmol}_{\mathrm{c}} \mathrm{dm}^{-3}$} \\
\hline \multirow{4}{*}{$0 \mathrm{~kg} \mathrm{ha-1}$} & $0-10$ & 4,68 & 1,02 & 38 & 19 & 0,96 & 0,41 & 0,45 \\
\hline & $10-20$ & 4,47 & 0,55 & 30 & 27 & 0,50 & 0,23 & 0,74 \\
\hline & $20-40$ & 4,41 & 0,4 & 25 & 26 & 0,25 & 0,14 & 0,58 \\
\hline & $40-60$ & 4,49 & 0,34 & 22 & 25 & 0,23 & 0,12 & 0,39 \\
\hline \multirow{4}{*}{$\begin{array}{l}60 \mathrm{~kg} \mathrm{ha}^{-1} \\
\text { como sulfato de amônio }\end{array}$} & $0-10$ & 4,50 & 1,85 & 41 & 20 & 0,91 & 0,37 & 0,71 \\
\hline & $10-20$ & 4,29 & 0,91 & 29 & 24 & 0,31 & 0,17 & 0,97 \\
\hline & $20-40$ & 4,39 & 0,62 & 22 & 25 & 0,29 & 0,15 & 0,66 \\
\hline & $40-60$ & 4,45 & 0,45 & 21 & 25 & 0,24 & 0,12 & 0,49 \\
\hline \multirow{4}{*}{$\begin{array}{c}120 \mathrm{~kg} \mathrm{ha}^{-1} \\
\text { como sulfato de amônio }\end{array}$} & $0-10$ & 4,47 & 1,02 & 39 & 29 & 0,89 & 0,36 & 0,69 \\
\hline & $10-20$ & 4,27 & 0,64 & 30 & 28 & 0,31 & 0,16 & 0,86 \\
\hline & $20-40$ & 4,35 & 0,42 & 27 & 28 & 0,20 & 0,12 & 0,62 \\
\hline & $40-60$ & 4,43 & 0,24 & 20 & 27 & 0,18 & 0,11 & 0,40 \\
\hline \multirow{4}{*}{$\begin{array}{c}240 \mathrm{~kg} \mathrm{ha}^{-1} \\
\text { como sulfato de amônio }\end{array}$} & $0-10$ & 4,43 & 2,52 & 36 & 32 & 0,86 & 0,34 & 0,67 \\
\hline & $10-20$ & 4,36 & 1,03 & 27 & 33 & 0,56 & 0,23 & 0,70 \\
\hline & $20-40$ & 4,32 & 0,66 & 20 & 29 & 0,22 & 0,13 & 0,65 \\
\hline & $40-60$ & 4,47 & 0,37 & 16 & 28 & 0,19 & 0,11 & 0,46 \\
\hline \multirow{4}{*}{$\begin{array}{l}120 \mathrm{~kg} \mathrm{ha}^{-1} \\
\text { como nitrato de amônio }\end{array}$} & $0-10$ & 4,48 & 1,03 & 38 & 24 & 0,50 & 0,25 & 0,87 \\
\hline & $10-20$ & 4,33 & 0,55 & 30 & 30 & 0,30 & 0,17 & 0,89 \\
\hline & $20-40$ & 4,32 & 0,45 & 22 & 31 & 0,14 & 0,11 & 0,74 \\
\hline & $40-60$ & 4,35 & 0,24 & 19 & 29 & 0,12 & 0,10 & 0,63 \\
\hline
\end{tabular}


Quadro 3. Características químicas e físicas de amostras de solo de um plantio de eucalipto aos 30 meses de idade (clone $\mathrm{AEC} 1528^{\circledR}$ ) sob doses e fontes de $\mathrm{N}$ distintas, em Itamarandiba, MG

\begin{tabular}{|c|c|c|c|c|c|c|c|c|c|c|}
\hline Dose N & Camada de Solo & $\mathrm{Zn}$ & $\mathrm{Fe}$ & Mn & $\mathrm{Cu}$ & B & Prem & $\operatorname{Areia}^{(2)}$ & Silte $^{(1)}$ & $\operatorname{Argila}^{(1)}$ \\
\hline & $\mathrm{cm}$ & & 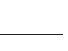 & $\mathrm{mg} \mathrm{dm}-3$ & & - & $\mathrm{mg} \mathrm{L}^{-1}$ & 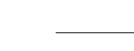 & dag $\mathrm{kg}^{-1}$ & - \\
\hline \multirow{4}{*}{$0 \mathrm{~kg} \mathrm{ha}^{-1}$} & $0-10$ & 0,28 & 162 & 12,49 & 0,51 & 1,29 & 8,64 & 8 & 7 & 85 \\
\hline & $10-20$ & 0,25 & 172 & 9,82 & 0,55 & 1,21 & 6,44 & 7 & 10 & 83 \\
\hline & $20-40$ & 0,18 & 143 & 5,78 & 0,49 & 0,95 & 6,41 & 7 & 10 & 83 \\
\hline & $40-60$ & 0,14 & 109 & 5,84 & 0,42 & 0,89 & 6,35 & 7 & 7 & 86 \\
\hline \multirow{4}{*}{$\begin{array}{c}60 \mathrm{~kg} \mathrm{ha}^{-1} \\
\text { como sulfato de } \\
\text { amônio }\end{array}$} & $0-10$ & 0,26 & 167 & 13,62 & 0,52 & 1,51 & 9,86 & 8 & 7 & 85 \\
\hline & $10-20$ & 0,20 & 160 & 8,19 & 0,55 & 1,18 & 6,90 & 8 & 9 & 83 \\
\hline & $20-40$ & 0,20 & 156 & 6,75 & 0,52 & 1,15 & 6,72 & 7 & 10 & 83 \\
\hline & $40-60$ & 0,20 & 112 & 6,10 & 0,43 & 1,11 & 6,45 & 6 & 9 & 85 \\
\hline \multirow{4}{*}{$\begin{array}{c}120 \mathrm{~kg} \mathrm{ha}^{-1} \\
\text { como sulfato de } \\
\text { amônio }\end{array}$} & $0-10$ & 0,32 & 161 & 14,04 & 0,53 & 1,57 & 8,57 & 8 & 9 & 83 \\
\hline & $10-20$ & 0,16 & 163 & 6,58 & 0,57 & 1,31 & 5,88 & 7 & 10 & 83 \\
\hline & $20-40$ & 0,09 & 136 & 5,14 & 0,49 & 0,99 & 5,88 & 7 & 10 & 83 \\
\hline & $40-60$ & 0,10 & 99 & 5,38 & 0,43 & 0,81 & 5,80 & 7 & 8 & 85 \\
\hline \multirow{4}{*}{$\begin{array}{c}240 \mathrm{~kg} \mathrm{ha}^{-1} \\
\text { como sulfato de } \\
\text { amônio }\end{array}$} & $0-10$ & 0,19 & 161 & 12,96 & 0,51 & 1,19 & 8,77 & 8 & 8 & 84 \\
\hline & $10-20$ & 0,19 & 167 & 10,79 & 0,56 & 0,90 & 6,69 & 8 & 10 & 82 \\
\hline & $20-40$ & 0,12 & 140 & 6,08 & 0,49 & 0,95 & 6,11 & 7 & 11 & 82 \\
\hline & $40-60$ & 0,08 & 106 & 4,80 & 0,44 & 0,87 & 6,31 & 8 & 7 & 85 \\
\hline \multirow{4}{*}{$\begin{array}{l}120 \mathrm{~kg} \mathrm{ha}^{-1} \\
\text { como nitrato de } \\
\text { amônio }\end{array}$} & $0-10$ & 0,29 & 158 & 10,54 & 0,51 & 1,51 & 8,81 & 7 & 8 & 85 \\
\hline & $10-20$ & 0,28 & 163 & 8,51 & 0,56 & 1,24 & 6,23 & 8 & 10 & 82 \\
\hline & $20-40$ & 0,20 & 151 & 6,65 & 0,49 & 0,97 & 5,95 & 8 & 8 & 84 \\
\hline & $40-60$ & 0,15 & 129 & 4,61 & 0,45 & 1,13 & 6,48 & 7 & 9 & 84 \\
\hline
\end{tabular}

(1) Silte e Argila: método da pipeta. ${ }^{(2)}$ Areia: peneiramento.

se a cubagem rigorosa da árvore abatida segundo método de Smalian, medindo os diâmetros a $0,1 \mathrm{~m}$ da base da planta e a $25,50,75$ e $100 \%$ da altura comercial. Cada componente da árvore (folhas, galhos, casca e lenho) foi pesado no campo.

Foram coletados discos do tronco da árvore, com lenho e casca, nas posições correspondentes a $0,1 \mathrm{~m}$ da base da planta e a $25,50,75$ e $100 \%$ da altura comercial, e amostras de folhas e galhos, para determinação do peso de matéria seca. Porções de casca e de lenho ("pó de serra" - obtido por meio de corte com motosserra na seção tranversal do lenho de $50 \mathrm{em} 50 \mathrm{~cm}$ ) foram homogeneizadas por componente, sendo retirada uma amostra composta de cada árvore. Realizou-se a análise química do material vegetal e calculou-se o conteúdo de nutrientes nos componentes da árvore, assim como a taxa de recuperação aparente de $\mathrm{N}$ aplicado.

Amostras de serapilheira foram coletadas em cada parcela. Para isso, coletaram-se oito amostras simples (quatro nas linhas e quatro nas entrelinhas de plantio), para compor uma amostra representativa da parcela, utilizando um gabarito de $0,5 \times 0,5 \mathrm{~m}$. Após determinação da massa fresca, retiraram-se amostras para análise química. As amostras de material vegetal (casca, lenho, galhos, folhas e serapilheira) foram secas em estufa de circulação forçada de ar a $65{ }^{\circ} \mathrm{C}$ por $72 \mathrm{~h}$ e moídas separadamente em moinho tipo Wiley equipado com peneira de $1 \mathrm{~mm}$.

Para determinação de $\mathrm{Ca}, \mathrm{Mg}, \mathrm{K}, \mathrm{S}, \mathrm{P}$ e de micronutrientes, conforme os métodos de dosagem descritos anteriormente (para solo), as amostras de cada componente vegetal e da serapilheira foram mineralizadas com mistura nítrico-perclórica na proporção $4: 1 \mathrm{v} / \mathrm{v}$, exceto para determinação do B. Na determinação do B, uma subamostra foi mineralizada por queima, a $550{ }^{\circ} \mathrm{C}$ em mufla, e solubilizada em ácido clorídrico $0,1 \mathrm{~mol} \mathrm{~L}^{-1}$. Os teores de $\mathrm{N}$ em cada componente vegetal, após digestão em ácido sulfúrico concentrado, foram quantificados pelo método Kjeldahl (Bremner \& Mulvaney, 1982).

Os dados referentes a características dendrométricas, produção de massa seca vegetal, teor e conteúdo de nutrientes foram submetidos à análise de variância. Posteriormente, realizou-se o desdobramento dos graus de liberdade de tratamentos e, por meio de regressões, avaliou-se o efeito das doses de $\mathrm{N}$, aplicado na forma de sulfato de amônio, na produção de massa seca vegetal e no teor e conteúdo de nutrientes nas árvores. Para avaliação do efeito das fontes de $\mathrm{N}$, foi estabelecido o contraste (N-sulfato de amônio vs. N-nitrato de amônio na dose de $120 \mathrm{~kg} \mathrm{ha}^{-1}$ ), adotando-se o nível de significância de até $5 \%$. Utilizou-se para o processamento 
dos dados o programa estatístico SAEG versão 9.1 (Funarbe, 2007).

\section{RESULTADOS E DISCUSSÃO}

Houve efeito das doses de $\mathrm{N}$ aplicado na forma de sulfato de amônio na produção volumétrica aos 30 meses de idade (Figura 1). A dose de $154 \mathrm{~kg} \mathrm{ha}^{-1} \mathrm{de}$ $\mathrm{N}$ proporcionou o volume máximo $\left(\hat{y}=95,22 \mathrm{~m}^{3} \mathrm{ha}^{-1}\right)$. Nesta dose, o volume de madeira foi $58,1 \%$ superior à produção sem adubação nitrogenada. A dose de $\mathrm{N}$, como sulfato de amônio, para obter $90 \%$ da produção máxima foi de $74 \mathrm{~kg} \mathrm{ha}^{-1}$, sendo o volume obtido $42,3 \%$ maior que sem a adubação nitrogenada. O volume de tronco na dose de $120 \mathrm{~kg} \mathrm{ha}^{-1}$ de $\mathrm{N}$ não diferiu $(p>0,05)$ entre a fonte de $\mathrm{N}$, sulfato de amônio e nitrato de amônio, indicando que a resposta ao sulfato de amônio deve-se ao suprimento de $\mathrm{Ne}$ não de S.

Resultados semelhantes foram encontrados por Silva et al. (2003), que observaram incremento linear, atingindo ganhos de até $44 \%$ em relação à testemunha, em clone híbrido de Eucalyptus aos 36 meses de idade com a aplicação de até $320 \mathrm{~kg} \mathrm{ha}^{-1}$ de N (30 \% na forma de nitrato de amônio e $70 \%$ na forma de sulfato de amônio) em Latossolo Vermelho textura média com $20 \mathrm{~g} \mathrm{~kg}^{-1}$ de matéria orgânica do solo (MOS). O fornecimento de $\mathrm{N}$, até $486 \mathrm{~kg} \mathrm{ha}^{-1}$ (primeira cobertura com ureia e a segunda e terceira com sulfato de amônio), proporcionou ganho linear no crescimento de clones de Eucalyptus em Espodossolos na região sul da Bahia em avaliação feita aos 24 meses por Araújo et al. (2003). Estes mesmos autores relataram incremento de até $109 \%$ no crescimento, em relação à testemunha.

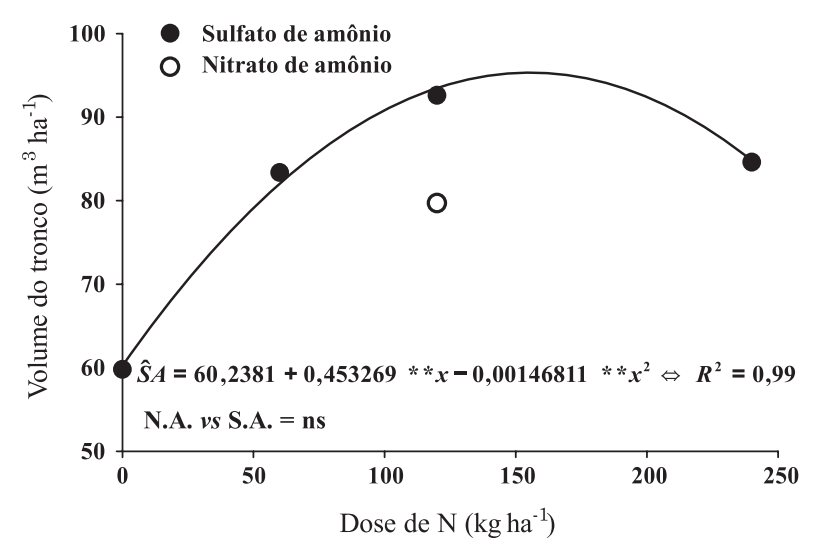

Figura 1. Volume do tronco do clone AEC1528 ${ }^{\circledR}$ de eucalipto, aos 30 meses de idade, em doses de $\mathrm{N}$ aplicado como sulfato de amônio (S.A.) e por nitrato de amônio (N.A.) na dose de $120 \mathrm{~kg} \mathrm{ha}^{-1}$. **: significativo a $1 \%$ e ns: não significativo até $10 \%$, respectivamente, pelo teste $\mathrm{F}$.
A demanda de $\mathrm{N}$ por eucalipto à idade de 4,5 anos, no Brasil, varia de 150 a $327 \mathrm{~kg} \mathrm{ha}^{-1}$ (Santana et al., 2008), com valores mais baixos em solos arenosos. Assim, respostas à aplicação de $\mathrm{N}$ podem ser esperadas em solos com teores mais baixos de MOS, geralmente arenosos, como os solos dos estudos de Silva et al. (2003) e de Araújo et al. (2003), ou ainda em locais onde as condições climáticas não favorecem a rápida decomposição da MOS.

Em diversos sítios no Uruguai, em solos com teores de MOS variando de 1,1 a $6,4 \mathrm{~g} \mathrm{~kg}^{-1}$, a aplicação de $\mathrm{N}$ em povoamentos de eucalipto seis meses após plantio resultou em aumentos na produção volumétrica avaliada aos dois anos de idade. Entretanto, nos povoamentos que receberam adubação mais tardia, aos 12 meses após plantio, os contrastes ortogonais estabelecidos entre grupos que receberam $\mathrm{N}$ e que não foram adubados não foram significativos. Somente a comparação realizada entre as fontes ureia e $\mathrm{NH}_{4} \mathrm{NO}_{3}$, em um dos sítios avaliados, foi significativa quanto à resposta em produção volumétrica (Perdomo et al., 2007).

Segundo Bennett et al. (1997), respostas à fertilização nitrogenada em $E$. globulus são relativamente comuns onde a disponibilidade de $\mathrm{N}$ do solo é baixa. O baixo teor de MOS e a possibilidade de perda de N por lixiviação são condições que, também, favoreceriam maior resposta do eucalipto à adubação nitrogenada, como detectado por Valeri et al. (1997). Estes autores observaram aumento em volume de tronco pela aplicação de $\mathrm{N}$ e de $\mathrm{K}$. O efeito de fontes e doses de vários macronutrientes sobre a produtividade de $E$. grandis cultivado em Neossolos Quartzarênicos aponta para ganhos de produtividade pela adição de NPK 15-00-15, porém não é claro se o efeito foi do $\mathrm{N}$ e, ou, do $\mathrm{K}$ aplicado (Stape \& Benedetti, 1997). Silva et al. (2000) verificaram que, para solos com teor elevado de $\mathrm{K}$, a resposta do $E$. grandis à aplicação de $\mathrm{N}$ foi linear até a dose máxima de $80 \mathrm{~kg} \mathrm{ha}^{-1}$. Também na Austrália, a aplicação de $202 \mathrm{~kg} \mathrm{ha}^{-1}$ de $\mathrm{N}$ e $90 \mathrm{~kg} \mathrm{ha}^{-1}$ $\mathrm{P}$ em E. globulus mais do que dobrou crescimento e o acúmulo de $\mathrm{N}$ em comparação com a testemunha (Cromer \& Williams, 1982).

No entanto, no presente estudo, o teor de $\mathrm{C}$ do solo acima de $30 \mathrm{~g} \mathrm{~kg}^{-1}$ e a textura muito argilosa seriam condições propícias a uma pequena ou nenhuma resposta do eucalipto à adubação nitrogenada. $\mathrm{O}$ elevado teor de argila oxídica e, consequentemente, a maior estabilização coloidal da MOS podem levar à menor taxa de decomposição da MOS (Pulrolnik et al., 2009), disponibilizando menos $\mathrm{N}$ para as plantas de eucalipto. É possível também que haja imobilização líquida de $\mathrm{N}$ durante os primeiros anos de decomposição dos resíduos da colheita. Parte da resposta do eucalipto ao sulfato de amônio pode ser atribuída ao $\mathrm{S}$, ainda que a diferença entre as fontes não tenha sido significativa. Outra 
possível explicação seria uma alteração da taxa de decomposição da MOS, aumentando a eficiência em mineralizar todo o $\mathrm{N}$ demandado pelas árvores de eucalipto. Gama-Rodrigues (1997) verificou, em estudo conduzido em várias regiões bioclimáticas brasileiras, que o solo foi incapaz de atender a toda a demanda de $\mathrm{N}$ nos três primeiros anos, mas que após o quaarto ou quinto ano a disponibilidade de $\mathrm{N}$ suplantava a demanda do eucalipto.

A reduzida contribuição do $\mathrm{N}$ mineralizável em áreas florestadas com $E$. grandis e híbridos de $E$. grandis $x$ urophylla no Estado de São Paulo, com idades variando de 1 a 11,4 anos, foi verificada por Pulito (2009). Nesses solos, com teores de MOS entre 18 e $55 \mathrm{~g} \mathrm{~kg}^{-1}$ e teores de argila entre 80 e $680 \mathrm{~g} \mathrm{~kg}^{-1}$, a razão entre $\mathrm{N}$ mineralizável e $\mathrm{N}$ total $(\mathrm{N} 0 / \mathrm{Nt})$ variou, na sua grande maioria, entre 10 e $16 \%$, uma indicação da baixa labilidade da MOS em solos sob povoamentos de eucalipto, do que resultaria um processo de decomposição mais lento. De fato, Pulito (2009) observou que, em média, nos povoamentos mais jovens a fertilização resultou num aumento de $12 \%$ de produtividade. Essa resposta caiu para $6 \%$ entre 3 e 4 anos de idade. Na idade de corte, não foi observada resposta à fertilização. Assim, nos estádios iniciais dos povoamentos, a fertilização nitrogenada pode acelerar o ritmo de crescimento das árvores, pois aumenta a disponibilidade de $\mathrm{N}$ numa fase em que as taxas de mineralização desse nutriente no solo e nos resíduos vegetais não conseguem atender à alta demanda das árvores.

Smerthurst et al. (2004), tentando estabelecer uma relação entre o crescimento de árvores de $E$. nitens na Austrália e a fertilização nitrogenada, observaram que as plantações em solos com baixos níveis desse nutriente expressaram deficiência deste nos anos iniciais pós-plantio. Eles observaram que altas doses de $\mathrm{N}$ (500 kg ha-1 de $\mathrm{N}$ no total) foram necessárias para maximizar o crescimento em muitos sítios, porém não houve evidências que sugerissem aplicação de $\mathrm{N}$ acima de $200 \mathrm{~kg} \mathrm{ha}^{-1}$ de $\mathrm{N}$ em uma única aplicação. Portanto, várias aplicações são necessárias para maximizar o crescimento. Outro dado importante relatado por Smerthurst et al. (2004) é que a disponibilidade de $\mathrm{N}$ no solo aumentou por um período de um a dois anos após as doses totais terem sido aplicadas. A taxa de crescimento das árvores aumentou nesse mesmo período, seguida por resposta menos pronunciada por alguns anos, durante os quais a reaplicação do $\mathrm{N}$ sustentou a taxa de crescimento.

Os resultados divergem dos encontrados por Santos (2001), para quem que a aplicação de N na forma de ureia não resultou em ganhos significativos de produção volumétrica na época da colheita de $E$. grandis em três regiões distintas, bem como dos resultados relatados por Gama-Rodrigues (1997).
Aos dados de produção de massa seca da parte aérea e doses de $\mathrm{N}$, foi possível ajustar uma curva quadrática (Figura 2a). Com base nessa equação, estimou-se que a dose de $143,3 \mathrm{~kg} \mathrm{ha}^{-1}$ de $\mathrm{N}$ foi a que proporcionou a produção máxima de massa seca (48,95 $\left.\mathrm{Mg} \mathrm{ha}^{-1}\right)$, com ganho máximo de produção de 47,2 \% em comparação com a testemunha. A dose de $\mathrm{N}$, como sulfato de amônio, para obtenção de $90 \%$ da produção máxima foi de $63 \mathrm{~kg} \mathrm{ha}^{-1}$, que levaria a um ganho de $32,4 \%$ em comparação à testemunha. A produção de massa seca obtida com $120 \mathrm{~kg} \mathrm{ha}^{-1}$ de $\mathrm{N}$ não diferiu estatisticamente se a fonte foi sulfato de amônio ou nitrato de amônio (Figura 2a). A adubação nitrogenada aumentou a quantidade de copa, com consequente aumento de área foliar e da captura de energia, como também relatado por Smethurst et al. (2003). Esses resultados corroboram os relatados por Godinho et al. (1997), referentes à adição de $85 \mathrm{~kg} \mathrm{ha}^{-1}$ de $\mathrm{N}$ em solo arenoso de cerrado sob povoamentos de $E$. camaldulensis, os quais encontraram incremento de $20 \%$ na massa seca da parte aérea das árvores aos três anos de idade. Pinkard et al. (2006) também observaram aumento da produção de folhas aos 12 meses após a aplicação de $300 \mathrm{~kg} \mathrm{ha}^{-1} \mathrm{de} \mathrm{N}$, em área total, em E. globulus com três anos de idade.

Apesar do aumento de massa seca da parte aérea, não se detectou variação significativa na massa seca da serapilheira com o aumento das doses de N aplicado como sulfato de amônio, tampouco diferenças significativas entre o $\mathrm{N}$ aplicado na forma de sulfato de amônio e nitrato de amônio na dose de $120 \mathrm{~kg} \mathrm{ha}^{-1}$ (Figura 2b). Em geral, há estreita relação entre o crescimento florestal e a produção de serapilheira (Miller, 1984; Gonçalves et al., 1997). Os resultados do presente estudo podem ser justificados pela idade relativamente jovem das árvores, o que contribui para menor descarte de folhas. Segundo Ferreira (1984), a longevidade das folhas em árvores de eucalipto na região do cerrado de Minas Gerais é de aproximadamente dois anos. Alternativamente, a maior produtividade e deposição de serapilheira podem ter sido contrabalanceadas pela maior taxa de decomposição devido ao maior teor de $\mathrm{N}$ no tecido.

De modo geral, os teores de macronutrientes e micronutrientes nas folhas não foram influenciados pelas doses de $\mathrm{N}$ aplicado na forma de sulfato de amônio (Quadro 4). Araújo et al. (2003) também não observaram grandes variações nos teores foliares de $\mathrm{N}$ com a aplicação de doses desse nutriente. Apenas os teores de $\mathrm{N}$ e B estão acima do adequado, e os de $\mathrm{P}, \mathrm{Ca}, \mathrm{Mn}$ e $\mathrm{Cu}$ são adequados em comparação com aqueles sugeridos por Gonçalves (1995). O contraste entre as duas fontes de $\mathrm{N}$ utilizadas na dose de $120 \mathrm{~kg} \mathrm{ha}^{-1}$ também não foi significativo. Isso indica que nenhum nutriente avaliado foi limitante ao crescimento com o aumento das doses de N.

Os conteúdos de macronutrientes na parte aérea, com exceção do $\mathrm{P}$, aumentaram de forma 

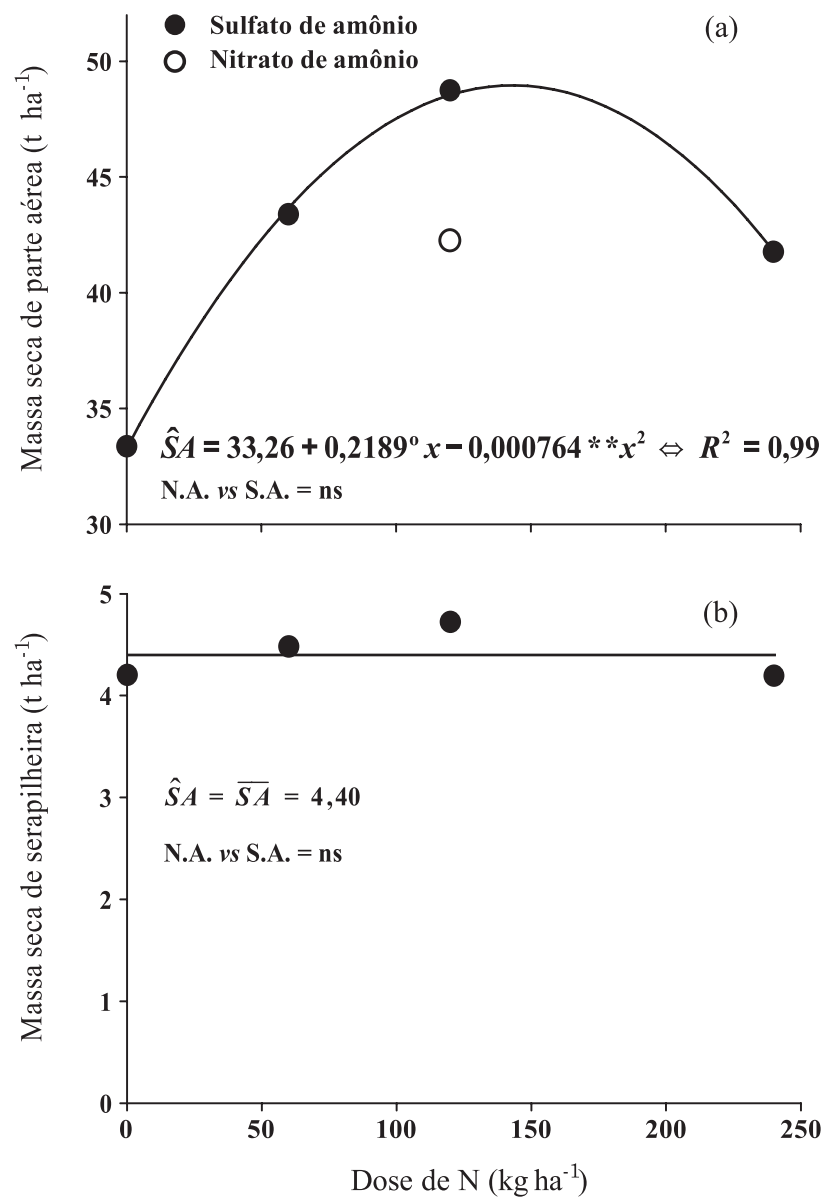

Figura 2. Massa seca da parte aérea (a) e da serapilheira (b) de um plantio do clone AEC1528 ${ }^{\circledR}$ de eucalipto aos 30 meses de idade sob doses de $\mathrm{N}$ aplicado como sulfato de amônio (S.A.) e por nitrato de amônio (N.A.) na dose de $120 \mathrm{~kg} \mathrm{ha}^{-1}$. o, **, ns: significativo a 10 e $1 \%$ e não significativo até $10 \%$, respectivamente, pelo teste $\mathrm{F}$. significativa com as doses de N (Quadro 5). Essa maior absorção - não apenas de $\mathrm{N}$, como também de outros nutrientes de maneira geral - está associada ao maior crescimento das plantas em resposta à adubação nitrogenada.

O conteúdo de $\mathrm{P}$ na planta manteve-se constante com o aumento da produção de massa seca, o que poderia ser um indicativo de que esse nutriente poderia limitar o crescimento. O nutriente mais absorvido pelo eucalipto foi o $\mathrm{N}$, conforme já relatado na literatura (Barros et al., 1990), seguindo a tendência dos vegetais superiores (Marques et al., 2006). Misra et al. (1998), estudando o efeito da adubação nitrogenada (600 kg ha-1 de N) com o sulfato de amônio e P (300 kg ha-1) em E. nitens, aos 2 e 26 meses, concluíram que a aplicação do fertilizante não influenciou o teor de $\mathrm{N}$ nas folhas, mas aumentou a concentração de $\mathrm{N}$ e $\mathrm{P}$ nos componentes das plantas, comparado com a não fertilização destas. Estes autores relatam aumento em crescimento da parte aérea pela segunda aplicação de $\mathrm{N}$ devido ao incremento maior de massa seca da parte aérea, em relação ao sistema radicular.

Na serapilheira não foram observadas diferenças significativas nos conteúdos de nutrientes com a aplicação de N (Quadro 5). Isso pode ser decorrente da ciclagem bioquímica, principalmente para os nutrientes móveis, ainda que as plantas sejam relativamente jovens. As espécies de eucalipto possuem elevada eficiência nutricional, devido à maior capacidade de retranslocação de nutrientes em relação a outras espécies florestais (Attiwill, 1980; Reis \& Barros, 1990). Os conteúdos dos vários nutrientes na serapilheira não foram alterados $(\mathrm{p}>0,05)$ pelas fontes de $\mathrm{N}$.

$\mathrm{O}$ conteúdo de $\mathrm{N}$ no povoamento mostrou relação positiva com a aplicação de N (Figura 3a), podendo

Quadro 4. Equações relacionando os teores foliares de macronutrientes (g kg-1) e de micronutrientes $\left(\mathrm{mg} \mathrm{kg}^{-1}\right)$ de um plantio do clone AEC1528 ${ }^{\circledR}$ de eucalipto, aos 30 meses de idade, com doses de $\mathrm{N}$ aplicado como sulfato de amônio (S.A.) e contraste entre sulfato de amônio e nitrato de amônio, na dose de $120 \mathrm{~kg} \mathrm{ha}^{-1}$

\begin{tabular}{|c|c|c|c|c|c|}
\hline \multirow{2}{*}{ Nutriente } & \multicolumn{2}{|c|}{$\hat{y}=f($ doses de S.A. $)$} & \multicolumn{3}{|c|}{$\hat{\mathrm{y}}=\mathrm{f}\left(\right.$ S.A. vs. N.A./dose $\left.120 \mathrm{~kg} \mathrm{ha}^{-1} \mathrm{~N}\right)$} \\
\hline & Equação & $\mathbf{R}^{2}$ & N.A. & S.A. & Significância \\
\hline $\mathrm{N}$ & $\hat{y}=\bar{y}=19,964$ & & 20,503 & 19,063 & ns \\
\hline $\mathrm{P}$ & $\hat{y}=\bar{y}=1,015$ & & 0,985 & 0,988 & ns \\
\hline $\mathrm{K}$ & $\hat{y}=\bar{y}=7,305$ & & 6,923 & 7,375 & ns \\
\hline $\mathrm{Ca}$ & $\hat{y}=\bar{y}=6,933$ & & 6,775 & 6,895 & ns \\
\hline $\mathrm{Mg}$ & $\hat{y}=\bar{y}=2,088$ & & 2,002 & 2,038 & ns \\
\hline $\mathrm{S}$ & $\hat{y}=\bar{y}=0,501$ & & 0,482 & 0,490 & ns \\
\hline $\mathrm{Zn}$ & $\hat{y}=\bar{y}=8,854$ & & 8,883 & 9,100 & ns \\
\hline $\mathrm{Fe}$ & $\hat{y}=\bar{y}=131,025$ & & 153,183 & 119,250 & ns \\
\hline $\begin{array}{l}\mathrm{Mn} \\
\mathrm{Cu}\end{array}$ & $\begin{array}{l}\hat{y}=\bar{y}=454,225 \\
\hat{y}=6,947-0,019 x+6,2510^{-5 \circ} x^{2}\end{array}$ & 0,99 & $\begin{array}{r}454,75 \\
7,133\end{array}$ & $\begin{array}{r}408,550 \\
5,650\end{array}$ & $\begin{array}{l}\text { ns } \\
\text { ns }\end{array}$ \\
\hline B & $\hat{y}=\bar{y}=78,784$ & & 80,368 & 79,852 & $\mathrm{~ns}$ \\
\hline
\end{tabular}

${ }^{\circ}$ e ns: significativo a $10 \%$ e não significativo até $10 \%$, respectivamente, pelo teste $\mathrm{F}$. 
Quadro 5. Equações relacionando o conteúdo de macronutrientes $\left(\mathrm{kg} \mathrm{ha}^{-1}\right)$ e de micronutrientes $\left(\mathrm{g} \mathrm{ha}^{-1}\right) \mathrm{na}$ parte aérea e na serapilheira de um plantio do clone $\mathrm{AEC} 1528^{\circledR}$ de eucalipto, aos 30 meses de idade, com doses de $\mathrm{N}$ aplicado como sulfato de amônio (S.A.) e contraste entre sulfato de amônio e nitrato de amônio (N.A.), na dose de $120 \mathrm{~kg} \mathrm{ha}^{-1}$

\begin{tabular}{|c|c|c|c|c|c|}
\hline \multirow{2}{*}{ Nutriente } & \multicolumn{2}{|l|}{$\hat{\mathbf{y}}=\mathbf{f}($ doses de S.A. $)$} & \multicolumn{3}{|c|}{$\hat{y}=f\left(\right.$ S.A. vs. N.A./dose $\left.120 \mathrm{~kg} \mathrm{ha}^{-1} \mathrm{~N}\right)$} \\
\hline & Equação & $\mathbf{R}^{2}$ & N.A. & S.A. & Significância \\
\hline & & & & Parte aérea & \\
\hline $\mathrm{N}$ & $\hat{y}=187,297+12,431 * x^{0,5}-0,644 x$ & 0,99 & 231,268 & 254,191 & ns \\
\hline $\mathrm{P}$ & $\hat{y}=\bar{y}=11,89$ & & 12,138 & 13,436 & ns \\
\hline $\mathrm{K}$ & $\hat{y}=113,269+0,686 x-0,002^{*} x^{2}$ & 1,00 & 135,315 & 162,029 & ns \\
\hline $\mathrm{Ca}$ & $\hat{y}=91,593+0,490^{\circ} x-0,001^{*} x^{2}$ & 0,99 & 114,175 & 127,429 & ns \\
\hline $\mathrm{Mg}$ & $\hat{y}=23,174+1,342^{\circ} x^{0,5}-0,061 x$ & 0,99 & 28,955 & 30,762 & ns \\
\hline $\mathrm{S}$ & $\hat{y}=4,567+0,379^{\circ} x^{0,5}-0,017^{\circ} x$ & 0,94 & 6,335 & 6,389 & ns \\
\hline $\mathrm{Zn}$ & $\hat{y}=\bar{y}=185,339$ & & 174,416 & 232,486 & ns \\
\hline $\mathrm{Fe}$ & $\hat{\mathrm{y}}=\overline{\mathrm{y}}=3010,75$ & & 3354,543 & 2662,814 & ns \\
\hline $\mathrm{Mn}$ & $\hat{y}=6252,447$ & & 6878,207 & 6497,388 & ns \\
\hline $\mathrm{Cu}$ & $\hat{y}=\bar{y}=117,962$ & & 170,334 & 116,894 & ns \\
\hline B & $\hat{y}=1424,408$ & & 1516,912 & $\begin{array}{l}1471,972 \\
\text { Serapilheira }\end{array}$ & ns \\
\hline $\mathrm{N}$ & $\hat{y}=\bar{y}=32,565$ & & 26,599 & 34,41 & ns \\
\hline $\mathrm{P}$ & $\hat{y}=\bar{y}=1,067$ & & 0,968 & 1,179 & ns \\
\hline $\mathrm{K}$ & $\hat{y}=\bar{y}=4,146$ & & 3,064 & 4,894 & ns \\
\hline $\mathrm{Ca}$ & $\hat{y}=\bar{y}=78,050$ & & 64,084 & 83,829 & ns \\
\hline $\mathrm{Mg}$ & $\hat{y}=\bar{y}=7,588$ & & 6,13 & 8,236 & ns \\
\hline $\mathrm{S}$ & $\hat{y}=\bar{y}=2,99$ & & 4,927 & 2,62 & ns \\
\hline $\mathrm{Zn}$ & $\hat{y}=\bar{y}=15,656$ & & 15,022 & 15,020 & ns \\
\hline $\mathrm{Fe}$ & $\hat{\mathrm{y}}=\overline{\mathrm{y}}=4944,807$ & & 3509,979 & 5586,524 & ns \\
\hline $\mathrm{Mn}$ & $\hat{y}=5202,74+30,450^{\circ} x$ & 0,87 & 9767,014 & 7175,962 & ns \\
\hline $\mathrm{Cu}$ & $\hat{\mathrm{y}}=\overline{\mathrm{y}}=46,578$ & & 37,544 & 48,704 & ns \\
\hline B & $\hat{y}=\bar{y}=458,269$ & & 380,96 & 538,787 & ns \\
\hline
\end{tabular}

${ }^{\circ}$, *, ns: significativo a 10 e $5 \%$ e não significativo até $10 \%$, respectivamente, pelo teste $\mathrm{F}$.
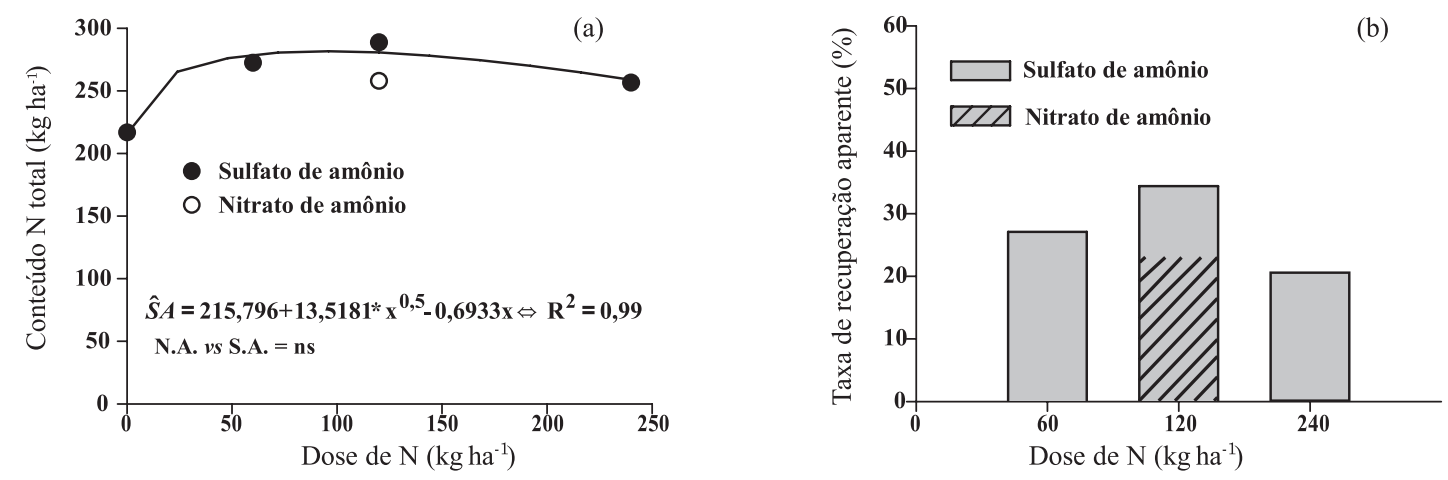

Figura 3. Conteúdo de N na parte aérea + serapilheira (a) e taxa de recuperação aparente do N do fertilizante (b) de um plantio do clone $\mathrm{AEC} 1528^{\circledR}$ de eucalipto, aos 30 meses de idade, influenciados por doses de $\mathrm{N}$ aplicado como sulfato de amônio (S.A.) e contraste entre sulfato de amônio e nitrato de amônio, na dose de $120 \mathrm{~kg} \mathrm{ha}^{-1}$. *, ns: significativo a $5 \%$ e não significativo até $10 \%$, respectivamente, pelo teste $\mathrm{F}$.

ser estimado pela equação $\hat{y}=215,796+13,5181 * x^{0,5}$ $-0,6933 x\left(R^{2}=0,99\right)$.
A taxa de recuperação aparente do $\mathrm{N}$ derivado do fertilizante chegou a um máximo de $34 \%$, na 
dose de $120 \mathrm{~kg} \mathrm{ha}^{-1}$ (Figura 3b). A recuperação decresceu para $21 \%$ na maior dose de N. Já a taxa de recuperação de $\mathrm{N}$ aplicado como nitrato de amônio, na dose de $120 \mathrm{~kg} \mathrm{ha}^{-1}$, foi de apenas $23 \%$. Esses resultados corroboram os obtidos por Ferreira (1986), que verificou a interação entre N e S na absorção de $\mathrm{N}$, ou, pelo menos, o efeito positivo da presença do S na absorção de N.

Poucos trabalhos no Brasil foram encontrados sobre a resposta do eucalipto à adubação nitrogenada. Nos que foram consultados, observa-se a diversidade das respostas e dados contrastantes com relação à taxa de recuperação do $\mathrm{N}$ do fertilizante. Por exemplo, Santos (2001) observou taxa de recuperação de até $45,5 \%$, dependendo da textura e do teor de MOS. Contudo, não houve consistência entre a resposta e a taxa de recuperação de N. Já Godinho (1997) observou taxa de recuperação de apenas 12,6\% em Neossolo Quartzarênico, porém ocorreu ganho de crescimento do eucalipto de $20 \%$. Em povoamentos avaliados por Pulito (2009), nos dois primeiros anos a produtividade relativa da testemunha foi, em média, $16 \%$ menor do que a observada nos tratamentos que receberam fertilização comercial nos solos de textura arenosa, $9 \%$ menor nos solos de textura média e $10 \%$ menor nos solos de textura argilosa e muito argilosa. Assim, o maior potencial de resposta à fertilização nitrogenada, em idade jovem, ocorreu nos solos onde foram encontrados os menores teores de $\mathrm{N}$ total e $\mathrm{N}$ mineralizável. No entanto, semelhante ao encontrado nos solos com textura mais argilosa, essa reposta desaparece ao final do ciclo da cultura, evidenciando que mesmo nos solos arenosos os estoques de $\mathrm{N}$ disponível no solo e a ciclagem de nutrientes são capazes de atender à demanda de $\mathrm{N}$ das árvores.

De maneira geral, tanto nos teores quanto no conteúdo não houve diferenças significativas na fração da matéria orgânica associada à fração mineral (MOAM) com o fornecimento de sulfato de amônio nas diferentes profundidades (Quadros 6 e 7). O conteúdo de $\mathrm{C}$ e $\mathrm{N}$ na MOS nas diferentes camadas de solo não foi influenciado pelas doses de $\mathrm{N}$ aplicadas como sulfato de amônio (Quadro 7).

Gama-Rodrigues (1997), trabalhando no sul da Bahia, não encontrou diferença significativa nos teores de $\mathrm{C}$ orgânico e $\mathrm{N}$ total de solos sob diferentes coberturas florestais. No entanto, grandes diferenças não eram esperadas na MOS global em curto prazo, com as mudanças ocorridas no manejo (Six et al.,

Quadro 6. Equações relacionando os teores de $\mathrm{N} \mathrm{e} \mathrm{C} \mathrm{(} \mathrm{g} \mathrm{kg}^{-1}$ da fração) na fração da matéria orgânica particulada (MOP) e na fração da matéria orgânica associada à fração mineral do solo (MOAM) de um plantio do clone $\mathrm{AEC} 1528^{\circledR}$, aos 30 meses de idade, com doses de $\mathrm{N}$ aplicado como sulfato de amônio (S.A.) e nitrato de amônio, na dose de $120 \mathrm{~kg} \mathrm{ha}^{-1}$, em profundidades distintas

\begin{tabular}{|c|c|c|c|c|c|c|}
\hline \multirow[t]{2}{*}{ Fração da MOS } & \multirow[t]{2}{*}{ Elemento } & \multicolumn{2}{|c|}{$\hat{y}=f(\operatorname{doses} d e$ S.A. $)$} & \multicolumn{3}{|c|}{$\hat{y}=f\left(\right.$ S.A. vs. N.A./dose $\left.120 \mathrm{~kg} \mathrm{ha}^{-1} \mathrm{~N}\right)$} \\
\hline & & Equação & $\mathbf{R}^{2}$ & N.A. & S.A. & Significância \\
\hline $\mathrm{g} \mathrm{kg}^{-1}$ & \multicolumn{6}{|c|}{$0-10 \mathrm{~cm}$} \\
\hline \multirow{2}{*}{ MOP } & $\mathrm{N}$ & $\hat{y}=\bar{y}=8,22$ & & 8,86 & 8,21 & * \\
\hline & $\mathrm{C}$ & $\hat{y}=\bar{y}=62,30$ & & 83,11 & 58,31 & * \\
\hline \multirow{3}{*}{ MOAM } & $\mathrm{N}$ & $\hat{y}=\bar{y}=7,68$ & & 7,76 & 7,83 & $\mathrm{~ns}$ \\
\hline & $\mathrm{C}$ & $\hat{y}=\bar{y}=28,96$ & & 31,82 & 30,00 & $\mathrm{~ns}$ \\
\hline & \multicolumn{6}{|c|}{$10-20 \mathrm{~cm}$} \\
\hline \multirow[t]{2}{*}{ MOP } & $\mathrm{N}$ & $\hat{y}=\bar{y}=7,77$ & & 7,8 & 7,58 & $\mathrm{~ns}$ \\
\hline & $\mathrm{C}$ & $\hat{y}=\bar{y}=38,09$ & & 38,55 & 32,82 & $\mathrm{~ns}$ \\
\hline \multirow{3}{*}{ MOAM } & $\mathrm{N}$ & $\hat{y}=7,391+0,002^{\circ} x$ & 0,87 & 7,78 & 7,46 & $\mathrm{~ns}$ \\
\hline & $\mathrm{C}$ & $\hat{y}=\bar{y}=25,92$ & & 27,11 & 25,70 & $\mathrm{~ns}$ \\
\hline & \multicolumn{6}{|c|}{$20-40 \mathrm{~cm}$} \\
\hline \multirow[t]{2}{*}{ MOP } & $\mathrm{N}$ & $\hat{\mathrm{y}}=\overline{\mathrm{y}}=7,50$ & & 7,9 & 7,56 & $\mathrm{~ns}$ \\
\hline & $\mathrm{C}$ & $\hat{y}=\bar{y}=23,25$ & & 33,05 & 24,16 & $\mathrm{~ns}$ \\
\hline \multirow{3}{*}{ MOAM } & $\mathrm{N}$ & $\hat{y}=\bar{y}=7,51$ & & 7,57 & 7,66 & $\mathrm{~ns}$ \\
\hline & $\mathrm{C}$ & $\hat{y}=\bar{y}=21,62$ & & 22,28 & 21,38 & $\mathrm{~ns}$ \\
\hline & \multicolumn{6}{|c|}{$40-60 \mathrm{~cm}$} \\
\hline \multirow[t]{2}{*}{ MOP } & $\mathrm{N}$ & $\hat{y}=\bar{y}=7,54$ & & 7,48 & 7,47 & $\mathrm{~ns}$ \\
\hline & $\mathrm{C}$ & $\hat{y}=\bar{y}=19,61$ & & 32,57 & 17,26 & $\mathrm{~ns}$ \\
\hline \multirow{2}{*}{ MOAM } & $\mathrm{N}$ & $\hat{y}=\bar{y}=7,46$ & & 7,46 & 7,55 & $\mathrm{~ns}$ \\
\hline & $\mathrm{C}$ & $\hat{y}=\bar{y}=18,56$ & & 20,38 & 18,13 & $\mathrm{~ns}$ \\
\hline
\end{tabular}

${ }^{\circ}$, ns: significativo a $10 \%$ e não significativo até $10 \%$, respectivamente, pelo teste $\mathrm{F}$. 
Quadro 7. Equações relacionando o conteúdo de $\mathrm{N} \mathrm{e} \mathrm{C} \mathrm{(} \mathrm{g} \mathrm{kg}^{-1}$ de solo) da fração da matéria orgânica particulada (MOP) e da fração da matéria orgânica associada à fração mineral do solo (MOAM) de um plantio do clone $\mathrm{AEC} 1528^{\circledR}$, aos 30 meses de idade, com doses de $\mathrm{N}$ aplicado como sulfato de amônio (S.A.) e nitrato de amônio, na dose de $120 \mathrm{~kg} \mathrm{ha}^{-1}$, em profundidades distintas

\begin{tabular}{|c|c|c|c|c|c|c|}
\hline \multirow{2}{*}{$\begin{array}{c}\text { Conteúdo } \\
\mathbf{Y}\end{array}$} & \multirow[t]{2}{*}{ Elemento } & \multicolumn{2}{|l|}{$\hat{y}=f($ doses de S.A. $)$} & \multicolumn{3}{|c|}{$\hat{y}=f\left(\right.$ S.A. vs. N.A./dose $\left.120 \mathrm{~kg} \mathrm{ha}^{-1} \mathrm{~N}\right)$} \\
\hline & & Equação & $\mathbf{R}^{2}$ & N.A. & S.A. & Significância \\
\hline & & & $0-10 \mathrm{~cm}$ & & & \\
\hline \multirow{2}{*}{ MOP } & $\mathrm{N}$ & $\hat{y}=\bar{y}=0,82$ & & 0,88 & 0,77 & * \\
\hline & $\mathrm{C}$ & $\hat{y}=\bar{y}=6,16$ & & 8,25 & 5,45 & $* *$ \\
\hline \multirow{2}{*}{ MOAM } & $\mathrm{N}$ & $\hat{y}=\bar{y}=6,91$ & & 6,99 & 7,09 & $\mathrm{~ns}$ \\
\hline & $\mathrm{C}$ & $\hat{y}=\bar{y}=26,10$ & & 28,66 & 27,18 & ns \\
\hline \multirow{3}{*}{ MOS } & $\mathrm{N}$ & $\hat{\mathrm{y}}=\overline{\mathrm{y}}=7,73$ & & 7,86 & 7,86 & ns \\
\hline & $\mathrm{C}$ & $\hat{\mathrm{y}}=\overline{\mathrm{y}}=32,25$ & & 36,9 & 32,63 & ns \\
\hline & & & $10-20 \mathrm{~cm}$ & & & \\
\hline \multirow{2}{*}{ MOP } & $\mathrm{N}$ & $\hat{y}=0,721-0,001 x+5,14 \cdot 10-6 * x^{2}$ & 0,98 & 0,73 & 0,64 & * \\
\hline & $\mathrm{C}$ & $\hat{\mathrm{y}}=\overline{\mathrm{y}}=3,31$ & & 3,58 & 2,74 & $\mathrm{~ns}$ \\
\hline \multirow{2}{*}{ MOAM } & $\mathrm{N}$ & $\hat{y}=\bar{y}=6,91$ & & 7,05 & 6,83 & $\mathrm{~ns}$ \\
\hline & $\mathrm{C}$ & $\hat{\mathrm{y}}=\overline{\mathrm{y}}=23,64$ & & 24,58 & 23,55 & ns \\
\hline \multirow{3}{*}{ MOS } & $\mathrm{N}$ & $\hat{y}=7,417+0,002^{\circ} x$ & 0,86 & 7,78 & 7,47 & ns \\
\hline & $\mathrm{C}$ & $\hat{\mathrm{y}}=\overline{\mathrm{y}}=26,95$ & & 28,15 & 26,28 & $\mathrm{~ns}$ \\
\hline & & & $20-40 \mathrm{~cm}$ & & & \\
\hline \multirow{2}{*}{ MOP } & $\mathrm{N}$ & $\hat{y}=\bar{y}=0,61$ & & 0,64 & 0,61 & $\mathrm{~ns}$ \\
\hline & $\mathrm{C}$ & $\hat{\mathrm{y}}=\overline{\mathrm{y}}=1,87$ & & 2,65 & 1,94 & ns \\
\hline \multirow{2}{*}{ MOAM } & $\mathrm{N}$ & $\hat{y}=\bar{y}=6,89$ & & 6,95 & 7,04 & $\mathrm{~ns}$ \\
\hline & $\mathrm{C}$ & $\hat{y}=\bar{y}=19,85$ & & 20,47 & 19,65 & ns \\
\hline \multirow{3}{*}{ MOS } & $\mathrm{N}$ & $\hat{\mathrm{y}}=\overline{\mathrm{y}}=7,50$ & & 7,59 & 7,65 & $\mathrm{~ns}$ \\
\hline & $\mathrm{C}$ & $\hat{\mathrm{y}}=\overline{\mathrm{y}}=21,72$ & & 23,13 & 21,58 & $\mathrm{~ns}$ \\
\hline & & & $40-60 \mathrm{~cm}$ & & & \\
\hline \multirow{2}{*}{ MOP } & $\mathrm{N}$ & $\hat{\mathrm{y}}=\overline{\mathrm{y}}=0,60$ & & 0,58 & 0,58 & $\mathrm{~ns}$ \\
\hline & $\mathrm{C}$ & $\hat{\mathrm{y}}=\overline{\mathrm{y}}=1,46$ & & 2,53 & 1,28 & $\mathrm{~ns}$ \\
\hline \multirow{2}{*}{ MOAM } & $\mathrm{N}$ & $\hat{\mathrm{y}}=\overline{\mathrm{y}}=6,87$ & & 6,88 & 6,95 & $\mathrm{~ns}$ \\
\hline & $\mathrm{C}$ & $\hat{y}=\bar{y}=17,06$ & & 18,8 & 16,72 & $\mathrm{~ns}$ \\
\hline \multirow{2}{*}{ MOS } & $\mathrm{N}$ & $\hat{\mathrm{y}}=\overline{\mathrm{y}}=7,47$ & & 7,46 & 7,54 & $\mathrm{~ns}$ \\
\hline & $\mathrm{C}$ & $\hat{\mathrm{y}}=\overline{\mathrm{y}}=18,52$ & & 21,33 & 18,00 & $\mathrm{~ns}$ \\
\hline
\end{tabular}

${ }^{\circ},{ }^{*},{ }^{* *}$, ns: significativo a 10,5 e $1 \%$ e não significativo até $10 \%$, respectivamente, pelo teste $\mathrm{F}$.

2002), especialmente neste estudo, tendo em vista o tempo relativamente curto entre a aplicação dos tratamentos e as avaliações realizadas.

Em relação à fração matéria orgânica particulada (MOP), não foram observadas variações significativas com a adição de doses de $\mathrm{N}$ na forma de sulfato de amônio (Quadros 6 e 7), com exceção do conteúdo de $\mathrm{N}$ na camada de solo de 10 a $20 \mathrm{~cm}$. Alguns autores sugerem que a fração da MOP responde às mudanças de uso da terra e no manejo do solo de forma seletiva e rápida (Cambardella \& Elliott, 1994; Chan, 1997; Guggenberger \& Zech, 1999; Lehmann et al., 2001; Franzluebbers \& Stuedemann, 2002), sendo, assim, tida como um indicador sensível das mudanças ocorridas na MOS global. No entanto, não foram detectadas alterações nos teores de $\mathrm{C}$ e $\mathrm{N}$ da MOP devido à adubação com sulfato de amônio (Quadro 6). O local da aplicação do adubo e a forma de amostragem podem ter influenciado esse resultado, pois a MOP é um compartimento dinâmico, com C relativamente desprotegido e decorrente das recentes adições de resíduos de plantas (Lehmann et al., 2001), com tempo de ciclagem da ordem de meses ou poucos anos (Balesdent, 1996). No entanto, parte da MOP pode ser fisicamente estabilizada dentro de agregados (Cambardella \& Elliott, 1994), e parte pode ter passado a C biologicamente estável (Skjemstad et al., 1990).

$\mathrm{O}$ contraste entre as fontes de $\mathrm{N}$ aplicadas na dose de $120 \mathrm{~kg} \mathrm{ha}^{-1}$ foi significativo para os teores e 
conteúdo de $\mathrm{C}$ e $\mathrm{N}$ na fração da MOP na camada de solo de 0 a $10 \mathrm{~cm}$ e para o conteúdo de $\mathrm{N}$ na camada de solo de 10 a $20 \mathrm{~cm}$, sendo os maiores valores observados para o nitrato de amônio (Quadros 6 e 7). Possivelmente, por causa da tendência de menor acúmulo de $\mathrm{N}$ nos componentes das plantas quando se aplicou $\mathrm{N}$ na forma de nitrato de amônio, maior quantidade de $\mathrm{N}$ vinda desse fertilizante foi incorporada à MOS, mais especificamente à MOP, contribuindo para aumentar o $\mathrm{C}$ dessa fração. Isso mostra a importância da adubação nitrogenada não apenas diretamente no aumento de produção, mas também na manutenção da produção por vários ciclos, pelo efeito do $\mathrm{N}$ na estabilização das frações mais humificadas da matéria orgânica (Stevenson, 1994).

\section{CONCLUSÕES}

1. A adubação nitrogenada promove aumentos de produção das árvores de eucalipto e nos conteúdos de N.

2. O sulfato de amônio como fonte de $\mathrm{N}$ não altera os teores de $\mathrm{C}$ e $\mathrm{N}$ nas frações da matéria orgânica particulada e da associada à fração mineral do solo.

3. A taxa de recuperação aparente de $\mathrm{N}$ do fertilizante aplicado é proporcional ao crescimento do eucalipto, atingindo o máximo de $34,4 \%$.

\section{AGRADECIMENTOS}

À Empresa ArcelorMittal Bioenergia, pela disponibilidade das áreas para instalação do experimento e pelo apoio na coleta dos dados.

À CAPES e ao CNPq, pelo contínuo suporte financeiro às pesquisas em nossos laboratórios.

\section{LITERATURA CITADA}

ABREU, C.A.; ABREU, M.F.; RAIJ, B.van \& BATAGLIA, O.C. Extraction of boron from soil by microwave heating for ICPAES determination. Comm. Soil Sci. Plant Anal., 25:3321-3333, 1994.

ALVAREZ V., V.H.; DIAS, L.E.; RIBEIRO, F.S.; SOUZA, R.B. \& FONSECA, C.A. Métodos de análises de enxofre em solos e plantas. Viçosa, MG, Universidade Federal de Viçosa, 2001. 131p.

ALVAREZ V., V.H.; NOVAIS, R.F.; DIAS, L.E. \& OLIVEIRA, J.A. Determinação e uso do fósforo remanescente. B. Inf. SBCS, 25:27-34, 2000.
ARAÚJO, E.F.; GAVA, J.L.; SOUZA, A.J. \& SILVEIRA, R.L.V.A. Crescimento de clones de Eucalyptus em resposta à aplicação de nitrogênio em Espodossolo no sul da Bahia. In: CONGRESSO BRASILEIRO DE CIÊNCIA DO SOLO, 29., 2003. Ribeirão Preto. Anais... Ribeirão Preto, Sociedade Brasileira de Ciência do Solo, 2003. CD ROM.

ASSOCIATIONS OF OFFICIAL ANALYTICAL CHEMISTS AOAC. Official methods of analysis of the Associations of Official Analytical Chemists. 12.ed. Washington, D.C., 1975. 1024p.

ATTIWILL, P.M. Nutrient cycling in a Eucalyptus oblique (L.Herit) forest. IV. Nutrient uptake and nutrient return. Austr. J. Bot., 28:199-222, 1980.

BALESDENT, J. The significance of organic separates to carbon dynamics and its modelling in some cultivated soils. Eur. J. Soil. Sci., 47:485-493, 1996.

BARROS, N.F. \& COMERFORD, N.B. Sustentabilidade da produção de florestas plantadas na região tropical. In: ALVAREZ V., V.H.; SCHAEFER, C.E.G.R.; BARROS, N.F.; MELLO, J.W.V. \& COSTA, L.M., eds. Tópicos em ciência do solo. Viçosa, MG, Sociedade Brasileira de Ciência do Solo, 2002. v.2. p.487-592.

BARROS, N.F.; NOVAIS, R.F. \& NEVES, J.C.L. Fertilização e correção do solo para o plantio do eucalipto. In: BARROS, N.F. \& NOVAIS, R.F., eds. Relação solo-eucalipto. Viçosa, MG, Folha de Viçosa, 1990. p.127-186.

BENNETT, L.T.; WESTON, C.J. \& ATTIWILL, P.M. Biomass, nutrient content and growth response to fertilisers of six-year-old Eucalyptus globulus plantations at three contrasting sites in Gippsland, Victoria. Austr. J. Bot., 45:103-121, 1997.

BRAGA, J.L. \& DEFELIPO, B.V. Determinação espectrofotométrica de fósforo em extratos de solos e plantas. R. Ceres, 21:73-85, 1974.

BREMNER, J.M. \& MULVANEY, C.S. Total nitrogen. In: PAGE, A.L., ed. Methods of soil analysis. Madison, American Society of Agronomy, 1982. p.595-624.

CAMBARDELLA, C.A. \& ELLIOT, E.T. Carbon and nitrogen dynamics of soil organic matter fractions from cultivated grassland soils. Soil Soil Sci. Soc. Am. J., 58:123-130, 1994.

CAMBARDELLA, C.A. \& ELLIOTT, E.T. Particulate soil organic-matter changes across a grassland cultivation sequence. Soil Sci. Soc. Am. J., 56:777-783, 1992.

CHAN, K.Y. Consequences of changes in particulate organic carbon in Vertisols under pasture and cropping. Soil Sci. Soc. Am. J., 61:1376-1382, 1997.

CROMER, R.N. \& WILLIAMS, E.R. Biomass and nutrient accumulation in a planted $E$. globules (Labill.) fertilizer trial. Austr. J. Bot., 30:265-378, 1982.

DEFELIPO, B.V. \& RIBEIRO, A.C. Análise química do solo. Metodologia. Viçosa, MG, Universidade Federal de Viçosa, 1997. 26p. (Boletim de Extensão, 29)

FERREIRA, M.G.M. An analysis of the future productivity of Eucalyptus grandis plantations in the cerrado region in Brazil; a nutrient cycling approach. Vancouver, University of British Columbia, 1984. 230p. (Tese de Doutorado) 
FERREIRA, F.A.S. A interação nitrato, fosfato e sulfato na absorção de fosfato e de sulfato no crescimento de eucalipto e no seu metabolismo de nitrato e sulfato. Viçosa, MG, Universidade Federal de Viçosa, 1986. 95p. (Tese de Mestrado)

FRANZLUEBBERS, A.J. \& STUEDEMANN, J.A. Particulate and non-particulate fractions of soil organic carbon under pastures in the Southern Piedmont USA. Environ. Poll., 116:53-62, 2002 .

FUNDAÇÃO ARTHUR BERNARDES - FUNARBE. SAEG - Sistema para Análises Estatísticas, Versão 9.1: - (www.ufv.br/ saeg), Viçosa, MG, Universidade Federal de Viçosa, 2007.

GAMA-RODRIGUES, E.F. Carbono e nitrogênio da biomassa microbiana do solo e da serapilheira de povoamentos de eucalipto. Seropédica, Universidade Federal Rural do Rio de Janeiro, 1997. 108p. (Tese de Doutorado)

GODINHO, V.P.C.; BARROS, N.F.; PEREIRA, P.R.G. \& CAN TARUTTI, R.B. Crescimento e recuperação de N e K por Eucalyptus camaldulensis, cultivado em solo arenoso de cerrado, em resposta ao modo de aplicação de adubo nitrogenado e potássico. In: IUFRO, 3., Salvador, 1997. Anais... Salvador, 1997. p.98-105.

GONÇALVES, J.L.M. Recomendações de adubação para Eucalyptus, Pinus e espécies típicas da Mata Atlântica. Piracicaba, 1995. p.1-23. (Documentos Florestais, 15)

GONÇALVES, J.L.M.; BARROS, N.F.; NAMBIAR, E.K.S. \& NOVAIS, R.F. Soil and stand management for shortrotation plantations. In: NAMBIAR, E.K.S. \& BROWN, A.G., eds. Management of soil, water, and nutrients in tropical plantation forests. Canberra, 1997. p.379-418. (ACIAR Monograph, 43)

GUGGENBERGER, G. \& ZECH, W. Soil organic matter composition under primary forest, pasture, and secondary forest succession, Region Huetar Norte, Costa Rica. For. Ecol. Manag., 124:93-104, 1999.

LEHMANN, J.; CRAVO, M.D.S. \& ZECH, W. Organic matter stabilization in a Xanthic Ferralsol of the central Amazon as affected by single trees: Chemical characterization of density, aggregate, and particle size fractions. Geoderma, 99:147-168, 2001

MARQUES, V.B.; PAIVA, H.N.; GOMES, J.M.; NEVES, J.C.L. \& BERNARDINO, D.C.S. Efeito de fontes e doses de nitrogênio sobre o crescimento inicial e qualidade de mudas de jacarandá-da-bahia (Dalbergia nigra (Vell.) Fr. All. ex Benth.). R. Árvore, 30:725-735, 2006.

MILLER, H.G. Dynamics of nutrient cycling in plantation ecosystems. In: BOWEN, G.D. \& NAMBIAR, E.K.S., eds. Nutrition of plantation forests. London, Academic Press, 1984. p.53-78.

MISRA, R.K.; TURNBULL, C.R.A.; CROMER, R.N.; GIBBONS, A.K.; LASALA, A.V. \& BALLARD, L.M. Below- and aboveground growth of Eucalyptus nitens in a young plantation. II. Nitrogen and phosphorus. For. Ecol. Manag., 106:295306, 1998.

PERDOMO, C.; DURÁN, J. \& LLOVET, P. Soil and plant indices for predicting eucalypt response to nitrogen in Uruguay. Soil Sci. Soc. Am. J., 71:1708-1718, 2007.
PINKARD, E.A.; BAILLIE, C.; PATEL, V. \& MOHAMMED, C.L. Effects of fertilising with nitrogen and phosphorus on growth and crown condition of Eucalyptus globulus Labill. experiencing insect defoliation. For. Ecol. Manag., 231:131-137, 2006.

PULITO, A.P. Resposta à fertilização nitrogenada e estoque de nitrogênio biodisponível em solos usados para plantações de Eucalyptus. Piracicaba, Escola Superior de Agricultura Luiz de Queiroz, 2009. 58p. (Tese de Mestrado)

PULROLNIK, K.; BARROS, N.F.; SILVA, I.R.; NOVAIS, R.F. \& BRANDANI, C.B. Estoques de carbono e nitrogênio em frações lábeis e estáveis da matéria orgânica de solos sob eucalipto, pastagem e cerrado no Vale do Jequitinhonha MG. R. Bras. Ci. Solo, 33:1125-1136, 2009.

REIS, M.G.F. \& BARROS, N.F. Ciclagem de nutrientes em plantios de eucalipto. In: BARROS, N.F. \& NOVAIS, R.F., eds. Relação solo-eucalipto. Viçosa, MG, Folha de Viçosa, 1990. p.265-302

RUIZ, H.A. Incremento da exatidão da análise granulométrica do solo por meio da coleta da suspensão (silte + argila). R. Bras. Ci. Solo, 29:297-300, 2005.

SANTANA, R.S.; BARROS, N.F.; NOVAIS, R.F.; LEITE, H.G. \& COMERFORD, N.B. Alocação de nutrientes em plantios de eucalipto no Brasil. R. Bras. Ci. Solo, 32:2723-2733, 2008.

SANTOS, M.L. Crescimento e alocação de biomassa e de nutrientes em eucalipto, decorrentes da aplicação de nitrogênio e potássio. Viçosa, MG, Universidade Federal de Viçosa, 2001. 62p. (Tese de Mestrado)

SILVA, C.R.; SILVEIRA, R.L.V.A.; CAMARGO, F.R.A.; HIGASHI, E.N. \& PATROCÍNIO, D.D. Efeito da aplicação de nitrogênio e potássio sobre o desenvolvimento inicial do $E u$ calyptus grandis e sua relação com a ocorrência da ferrugem (Puccinia psidii). In: FERTBIO, 2000. Anais...Santa Maria, Sociedade Brasileira de Ciência do Solo, 2000. CD-ROM.

SILVA, C.R.; SILVEIRA, R.L.V.A.; CAMARGO, F.R.A.; PATROCÍNIO, D.D. \& HIGASHI, E.N. Crescimento de clone híbrido de Eucalyptus em função da aplicação de nitrogênio na presença e ausência de potássio. In: CONGRESSO BRASILEIRO DE CIÊNCIA DO SOLO, 19., Ribeirão Preto, 2003. Anais...Ribeirão Preto, Sociedade Brasileira de Ciência do Solo, 2003. CD-ROM.

SIX, J.; CALLEWAERT, P.; LENDERS, S.; DE GRYZE, S.; MORRIS, S.J.; GREGORICH, E.G.; PAUL, E.A. \& PAUSTIAN, $\mathrm{K}$. Measuring and understanding carbon storage in afforested soils by physical fractionation. Soil Sci. Soc. Am. J., $66: 1981-1987,2002$

SKJEMSTAD, J.O.; LE FEUVRE, R.P. \& PREBBLE, R.E. Turnover of soil organic matter under pasture as determined by ${ }^{13} \mathrm{C}$ natural abundance. Austr. J. Soil Res., 28:267-276, 1990.

SMETHURST, P.; BAILLIE, C.; MARIA CHERRY, M. \& HOLZ, G. Fertilizer effects on LAI and growth of four Eucalyptus nitens plantations. For. Ecol. Manag., 176:531-542, 2003

SMETHURST, P.; HOLZ, G.; MORONI, M. \& BAILLIE, C. Nitrogen management in Eucalyptus nitens plantations. For Ecol. Manag., 193:63-80, 2004. 
STAPE, J.L. \& BENEDETTI, V. Decréscimo de produtividade e respostas da brotação do Eucalyptus grandis à fertilização com macronutrientes em Areia Quartzosa no estado de São Paulo-Brasil. In: IUFRO, 3, Salvador, 1997. Anais... Salvador, 1997. p.112-117.

STEVENSON, F.J. Humus chemistry: Genesis, composition, reactions. New York, Willey \& Sons, 1994. 496p.
VALERI, S.V.; ALVARENGA, S.F.; MARTINS, M.I.E.G. \& BANZATTO, D.A. Ganhos econômicos com aplicações de nitrogênio, potássio e calcário dolomítico em povoamento de Eucalyptus urophylla S. T. Blake. In: IUFRO, 4., Salvador. Anais... Salvador, 1997. p.138-141. 